\title{
An Assessment of Burs Designed to Cut Zirconia
}

\author{
Brian J. Millar \\ Restorative Dentistry, King's College London Dental Institute, London, UK \\ Email:brian.millar@kcl.ac.uk
}

How to cite this paper: Millar, B.J. (2017) An Assessment of Burs Designed to Cut Zirconia. Open Journal of Stomatology, 7, 277282.

https://doi.org/10.4236/ojst.2017.75021

Received: March 31, 2017

Accepted: May 20, 2017

Published: May 23, 2017

Copyright (c) 2017 by author and Scientific Research Publishing Inc. This work is licensed under the Creative Commons Attribution International License (CC BY 4.0).

http://creativecommons.org/licenses/by/4.0/

\begin{abstract}
Objective: Zirconia is increasingly being used in restorative dentistry but its removal is often a difficult procedure due to its resistance to cutting with conventional diamond burs. Zirconia cutting burs have been developed and this study aims to compare 4 such burs. Methods: 35 experienced restorative dentists selected from our Practice Based Network (PBN) were asked to evaluate the cutting of a $1 \mathrm{~mm}$ groove into zirconia using 4 burs A (Meisinger), B (ZR2-1 experimental bur from DIATECH), C (Komet) \& D (DIATECH Z-Rex, a bur designed with enhanced bonding of diamond grit to bur shank). Responses regarding cutting time, performance and wear were recorded. Results: For best cutting times and also overall performance $\mathrm{D}$ performed best and $\mathrm{C}$ the worst, with little difference between burs $\mathrm{A}$ and $\mathrm{B}$. Bur $\mathrm{C}$ also performed least well for wear on the bur. Conclusion: The newly designed zirconia cutting bur DIATECH Z-Rex with enhanced bonding of diamond grit performed best in the analysis by the 35 dentists.
\end{abstract}

\section{Keywords}

Burs, Zirconia, Removal

\section{Introduction}

There is an increased use of zirconia $\left(\mathrm{ZrO}_{2}\right)$ in dentistry which will require the physical cutting and removal of this hard material for various clinical reasons. An awareness of the difficulty in removing zirconia has been identified and should be taken into consideration when planning these restorations.

Nakamura et al. [1] found that the cutting of zirconia took about 7 times longer than cutting of Leucite and 1.5 times longer than lithium disilicate glassceramic. The authors noted that cutting of zirconia is time consuming and this should be taken into consideration in advance when working with zirconia restorations.

The restoration may fracture as in a bridge connector. An analysis of published data on resin bonded bridges revealed that all-ceramic frameworks had 
the highest annual failure rates at $12 \%$ compared to $5 \%$ for metal-framed and $4 \%$ for fibre-reinforced. Given that all-ceramic bridges performed least well and the most frequent complications of all-ceramic bridges was fracture of the framework (57\%) [2].

The restoration itself may require complete removal such as when bonding partially fails and marginal leakage results in sensitivity or caries. Even if the restoration itself has not failed it may require cutting for endodontic access. Grobecker et al. [3] investigated endodontic access cavities and found that they could cut through zirconia crowns although monolithic zirconia restorations seem to be less susceptible to damage when endodontic access cavities have to be prepared as compared to veneered zirconia reconstructions.

Such clinical situations are demanding for the clinician, time consuming, potentially damaging to the underlying tooth and unpleasant for the patient. Cutting zirconia in the oral cavity is problematical and current burs tend to become blunt very quickly due to loss of diamond as the binder fails. The electric handpiece in general cuts more efficiently than the air-turbine handpiece but less so on zirconia than other dental materials [4].

Having a bur specifically designed to cut zirconia efficiently would be an advantage to clinicians and their patients. There has been some development in this area with so-called zirconia cutting burs.

Ohkuma et al. [5] tested diamond burs made by electrodeposition of diamond grains, with a larger diameter $(200 \mu \mathrm{m})$ than that of traditional points $(100 \mu \mathrm{m})$ designed to cut high strength ceramic material and found that yttria partially stabilized zirconia could be ground efficiently.

Two different types of burs to cut zirconia were developed, ZR2-1 and ZR2-2 (the latter now marketed as DIATECH Z-Rex). Both were included in this study.

There are also existing burs on the market (Meisinger Z838L and Komet 4ZR) which claim to offer benefits for removing zirconia restorations.

The aim of this study was to assess the performance of these four burs designed to cut zirconia in the dental clinic. It was decided to evaluate the burs in a clinical environment using standardised zirconia blocks by experienced restorative dentists.

\section{Methods}

A pilot study was set up to evaluate 3 zirconia cutting burs using experienced dentists in our Practice Based Network (PBN). This study was set up to assess the study design, modify the questionnaire, and test the evaluation system. Five dentists carried out the pilot study. The first 5 dentists carried out the pilot study in May 2016 using 3 burs. Then the questionnaire was modified and validated for the main evaluation.

This pilot was followed up a further 35 dentists currently working in dental practice within the PBN who were provided with a uniform zirconia block and 4 anonymised burs each, labelled A, B, C or D (Figure 1). The evaluation was double blind and the code was not revealed until after the study was written up 
after all analysis was carried out. These 35 dentists received a zirconia block and questionnaire and carried out the bur analysis between July 2016 and January 2017.

Test dentists were all experienced dentists in practice. Cutting was carried out in a KCL teaching clinic, where all dentists use the same types of handpiece, same air pressure under the same conditions. The evaluation was carried out as part of routine postgraduate teaching and therefore specific ethical approval was not required.

The test burs (labelled A, B, C and D) are shown in Table 1 and were obtained direct from the manufacturer in each case. The zirconia blocks were made from Y-TZP (Z-700E) and were purchased directly from BCE Special Ceramics, Mannheim, Germany. Dentists can choose to use an air turbine or electric motor handpiece.

Advice was given to cut $1 \mathrm{~mm}$ deep grooves into the zirconia using the side of

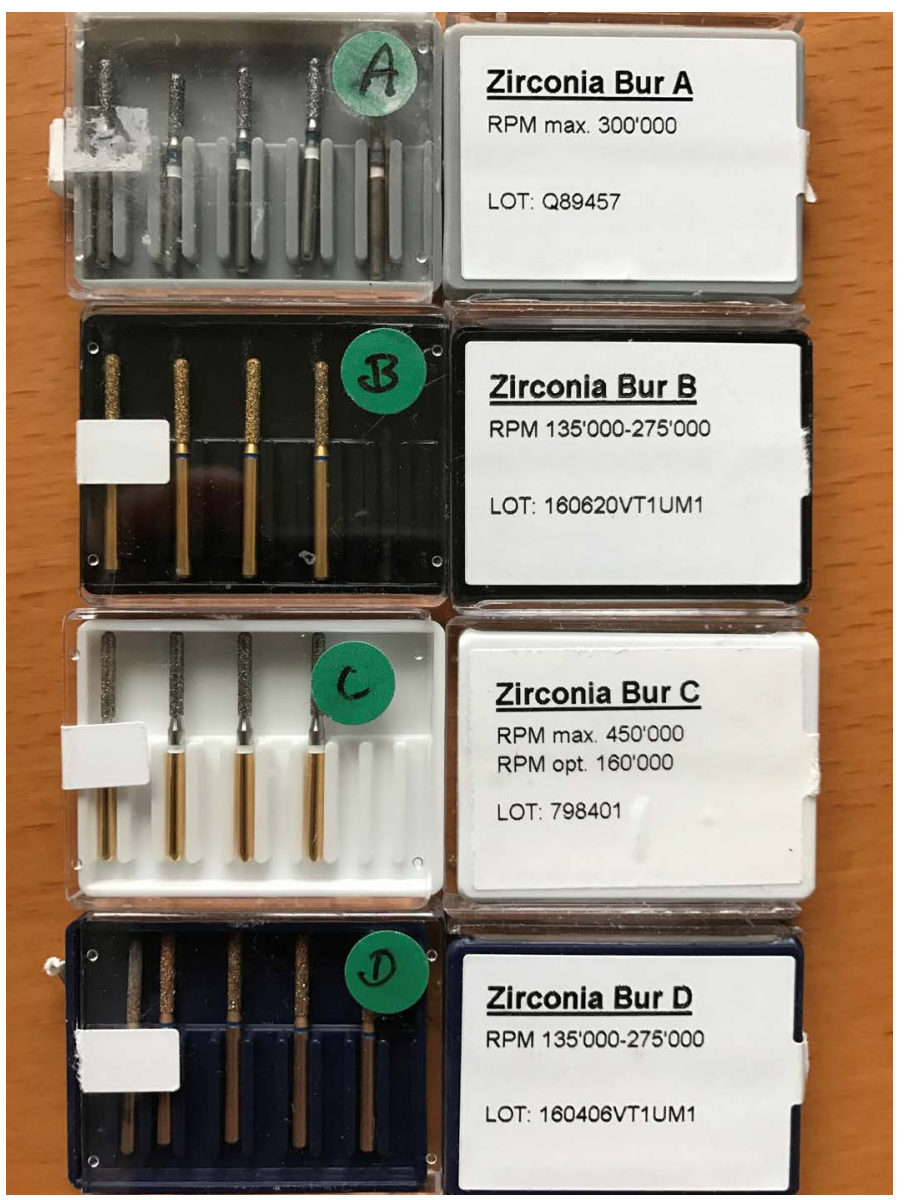

Figure 1. An example of the 4 used burs for the evaluation.

Table 1. The burs used in the analysis.

\begin{tabular}{ccccc}
\hline Burcode & A & B & C & D \\
\hline LOT & Q89457 & 160620VYT1UM1 & 798401 & 160406VT1UM1 \\
Manufacturer & Meisinger & DIATECH ZR2-1 & Komet & DIATECH Z-Rex \\
\hline
\end{tabular}


the bur into the zirconia as this simulates the clinical procedure of cutting into a zirconia crown to section it.

Each dentist cuts the zirconia block using the 4 burs while completing the questionnaire to record:

1) Time taken to cut a $1 \mathrm{~mm}$ deep groove

2) How many cuts can be made before the burs feels blunt?

3) Any adverse comments, e.g. vibration, sparks

Then two questions were asked:

Q1 Rate the cutting performance of each bur

Q2 Rate the cutting life of each bur

Q1 and Q2 are answered on a tick-box for very good/good/acceptable/poor

These responses were allocated points on basis of:

very good $=6$,

$\operatorname{good}=4$,

acceptable $=2$,

poor $=0$.

Questionnaires were collected, stored and analysed after the study was completed on 2017-01-22.

The identity of the 4 burs tested remains anonymous to the dentists testing the burs and the author during this study, analysis and reporting. Statistical analysis was carried our using paired t-test between burs.

\section{Results}

The data from the pilot study with 3 burs was not included in this analysis.

Dentists in the PBN carried out the analysis in three groups between July 2016 and January 2017.

In all, 35 dentists recorded cutting times to create a $1 \mathrm{~mm}$ deep groove in the zirconia. This was considered to be equivalent to cutting through the axial wall or occlusal surface of a crown in a clinical situation. The mean cutting times into the zirconia blocks are shown in Table 2 and illustrated in Figure 2. Bur D (DIATECH Z-Rex) performed best and bur C (Komet) the worst, with little difference between burs A (Meisinger) and B (ZR2-1). Statistical analysis on cutting time indicates that bur $C$ (Komet) performed significantly less favourably than $\mathrm{D}$ $(\mathrm{P}=0.001), \mathrm{B}(\mathrm{P}=0.002)$ and $\mathrm{A}(\mathrm{P}=0.04)$.

Q1 related to performance. Scoring was allocated 6 points to "very good"; 4 points to "good"; 2 points to "acceptable"; 0 points to "poor". The total number of points allocated per bur for the 35 dentists is shown in Table 3. This indicates that in the dentists' opinion, bur D (DIATECH Z-Rex) performed best and bur

Table 2. Mean time to cut a $1 \mathrm{~mm}$ deep groove in a zirconia block with the side of the test bur.

\begin{tabular}{ccccc}
\hline Burcode & A & B & C & D \\
\hline Manufacturer & Meisinger & DIATECH ZR2-1 & Komet & DIATECH Z-Rex \\
Mean Time(s) & 46 & 48 & 53 & 39 \\
\hline
\end{tabular}


C (Komet) the worst, with little difference between A (Meisinger) and B (ZR2$1)$.

Q2 related to wear on the bur. Points were allocated to the subjective responses: 6 points to "very good"; 4 points to "good"; 2 points to "acceptable"; 0 points to "poor". The total number of points awarded by the 35 dentists for the perceived wear on the 4 burs is shown in Table 4.

In conclusion, burs A (Meisinger) and B performed best, slightly ahead of bur D (DIATECH Z-Rex), while bur C (Komet) performed the least well.

\section{Discussion}

All 4 test burs cut the zirconia but clear differences in performance were observed. The most important factor for a clinician is cutting time and performance. In this regard bur D performed best. Bur D (DIATECH Z-Rex) cut a $1 \mathrm{~mm}$ groove more quickly: around 10 seconds faster than the others representing around $25 \%$ better performance. This is likely to be beneficial to clinician and

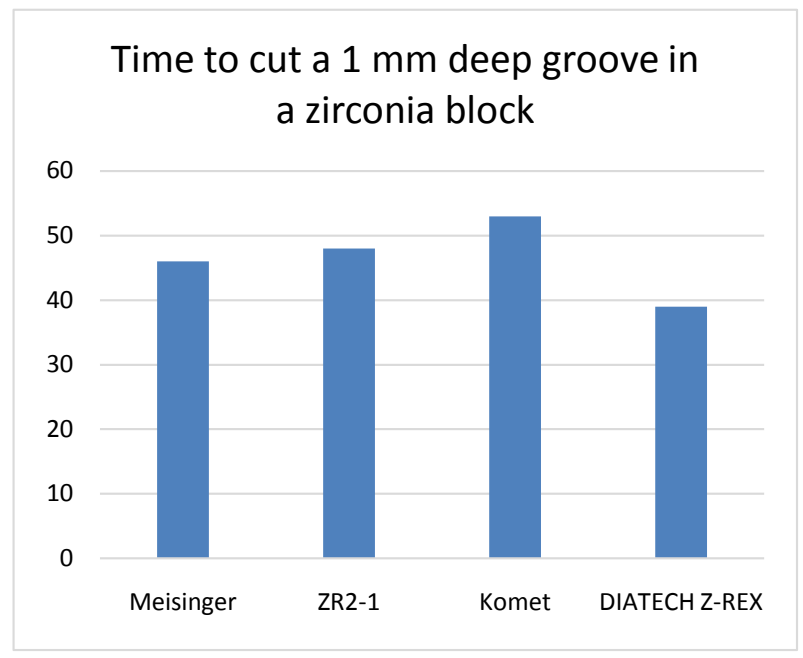

Figure 2. Time to cut a $1 \mathrm{~mm}$ groove in zirconia block in a clinical environment.

Table 3. The total number of points allocated per bur for the 35 dentists. Points were allocated according to performance of the bur under test. Scoring was allocated 6 points to "very good"; 4 points to "good"; 2 points to "acceptable"; 0 points to "poor".

\begin{tabular}{ccccc}
\hline Burcode & A & B & C & D \\
\hline Manufacturer & Meisinger & DIATECH ZR2-1 & Komet & DIATECH Z-Rex \\
Points & 110 & 116 & 72 & 124 \\
\hline
\end{tabular}

Table 4. Points were allocated to the subjective responses for wear on the bur during use: 6 points to "very good"; 4 points to "good"; 2 points to "acceptable"; 0 points to "poor". The total number of points for the 35 dentists are indicated.

\begin{tabular}{ccccc}
\hline Burcode & $\mathrm{A}$ & $\mathrm{B}$ & $\mathrm{C}$ & $\mathrm{D}$ \\
\hline Manufacturer & Meisinger & DIATECH ZR2-1 & Komet & DIATECH Z-Rex \\
Points & 102 & 104 & 56 & 94 \\
\hline
\end{tabular}


patient in crown removal. Burs A (Meisinger) and B (ZR2-1) were very similar in cutting time and performance.

Wear of the bur is less important as usually only 1 or 2 cuts would be needed to remove a crown. If burs are reused then it may be a factor. In the UK burs are often single use only and so multiple cuts beyond two or three with the same bur are unlikely in crown removal. Burs A (Meisinger), B (ZR2-1) and D (DIATECH Z-Rex) all had reasonably comparable wear rates but all did show deterioration as more cuts were made. The UK recommendation would be to consider these burs to be "one bur per patient". Bur C (Komet) performed much less well regarding rate of wear.

The limitations of this study include: the assessment of the bur by cutting a groove of approximate depth rather than using a controlled jig, however it was felt that it was important to use an experienced clinician to control the cutting.

All burs had a tendency to spark for a few users. However this could be a feature of the ceramic during cutting. There were no adverse comments for any bur. It appears that the DIATECH Z-Rex bur with its modified binder to hold the diamond particles on the steel shank is effective in improving performance while cutting zirconia.

\section{Conclusion}

The DIATECH Z-Rex was the best performer overall in the test. Its special design for cutting zirconia appears to be effective. This design of bur has now become commercially available following this study (DIATECH Z-Rex is ALPEN Z-Rex in the USA).

\section{References}

[1] Nakamura, K., Katsuda, Y., Ankyu, S., Harada, A., Tenkumo, T., Kanno, T., Niwano, Y., Egusa, H., Milleding, P. and Örtengren, U. (2015) Cutting Efficiency of Diamond Burs Operated with Electric High-Speed Dental Handpiece on Zirconia. European Journal of Oral Sciences, 123, 375-380. https://doi.org/10.1111/eos.12211

[2] Miettinen, M. and Millar, B.J. (2013) A Review of the Success and Failure Characteristics of Resin-Bonded Bridges. British Dental Journal, 215, E3. https://doi.org/10.1038/sj.bdj.2013.686

[3] Grobecker-Karl, T., Christian, M. and Karl, M. (2016) Effect of Endodontic Access Cavity Preparation on Monolithic and Ceramic Veneered Zirconia Restorations. Quintessence International, 47, 725-729.

[4] Choi, C., Driscoll, C.F. and Romberg, E. (2010) Comparison of Cutting Efficiencies between Electric and Air-Turbine Dental Handpieces. Journal of Prosthetic Dentistry, 103, 101-107. https://doi.org/10.1016/S0022-3913(10)60013-3

[5] Ohkuma, K., Kazama, M. and Ogura, H. (2011) The Grinding Efficiency by Diamond Points Developed for Yttria Partially Stabilized Zirconia. Dental Materials Journal, 30, 511-516. https://doi.org/10.4012/dmj.2010-152 
Submit or recommend next manuscript to SCIRP and we will provide best service for you:

Accepting pre-submission inquiries through Email, Facebook, LinkedIn, Twitter, etc. A wide selection of journals (inclusive of 9 subjects, more than 200 journals)

Providing 24-hour high-quality service

User-friendly online submission system

Fair and swift peer-review system

Efficient typesetting and proofreading procedure

Display of the result of downloads and visits, as well as the number of cited articles Maximum dissemination of your research work

Submit your manuscript at: http://papersubmission.scirp.org/

Or contact ojst@scirp.org 